\title{
O Incentivo ao Programa de Saúde da Família e seu Impacto sobre as Grandes Cidades
}

\author{
RUBENARAUJO DE MATTOS
}

\section{RESUMO}

Este trabalho discute a questão dos incentivos financeiros ao PSF, na perspectiva de sua transformação, no sentido de adaptá-los à necessidade de expansão do PSF nas grandes cidades. Analisamos, inicialmente, o contexto no qual a proposta de incentivo foi formulada, e as razōes para a ênfase na cobertura do PSF. Em seguida, discutimos o critério de cálculo do incentivo em vigor, analisando em que medida ele contempla as necessidades dos gestores das grandes cidades. Por fim, indicamos um elenco de possibilidades de introdução de novas regras, que elevem o patamar de pagamento do Governo federal por equipe do PSF a partir de um certo número de equipes implantadas ou, alternativamente, de um número absoluto de pessoas cobertas, preservando os critérios atuais para todos os municípios que nāo tenham alcançado esse patamar.

Palavras-chave: Programa de Saúde da Família; financiamento de políticas públicas; saúde nas grandes cidades. 
O Programa de Saúde da Família (PSF), criado em 1994, tem-se difundido bastante no país, e é apresentado como uma estratégia de mudança do modelo assistencial. Pelo menos uma parte dessa difusão se deve aos incentivos financeiros introduzidos pelo Ministério da Saúde. Em dezembro de 2000, o programa já estava implantado em um grande número de municípios, abarcando pouco mais de um quinto da população brasileira (Levcovitz et al., 2001).

É notório que o percentual de municípios com o programa tem crescido mais rapidamente do que o percentual da população coberta, o que pode ser atribuído, pelo menos em parte, à maior dificuldade de sua implantação nas cidades que concentram grande contingente populacional. De fato, a difusão do PSF nas grandes cidades tem sido mais problemática do que nas cidades menores ${ }^{2}$.

Segundo o Datasus, em junho de 2000, apenas três grandes cidades apresentavam coberturas significativamente superiores a $50 \%$, a saber: Sobral e Maracanaú, ambas no Ceará, e Camaragibe, em Pernambuco. Além dessas, apenas Palmas, no Tocantins, e Arapiraca, na Bahia, tinham cobertura de cerca de $50 \%$ da população. Essas cinco cidades têm menos de 200 mil habitantes. Mesmo levando-se em conta a defasagem dos dados disponibilizados, trata-se de um número bem reduzido em relação ao total de grandes cidades no Brasil.

Seriam os incentivos existentes insuficientes para promover a saúde da família nas grandes cidades? Que alternativas poderiam ser pensadas? Essas duas questões indicam o tema deste trabalho. Pretendemos examinar aqui, ainda que preliminarmente, a relação entre as alternativas de financiamento do PSF pelo Governo federal e seu poder de estímulo ao desenvolvimento do PSF nas grandes cidades.

Parece oportuno examinar algumas questões que têm atravessado o debate sobre o PSF e que incidem sobre os pressupostos básicos do modelo de incentivo financeiro instituído pelo Governo federal. Num segundo momento, procuraremos analisar os dispositivos de cálculo do incentivo ao PSF na sua forma atual, implantada em 1999. Após analisar o impacto desse critério sobre as grandes cidades, indicando sua insuficiência, exploraremos duas linhas distintas de dispositivos voltados especificamente para as grandes cidades: a aplicação dos mesmos critérios de faixas de cobertura em distritos ou subdivisões das grandes cidades e a fixação de um valor do incentivo por equipe, para municípios que superem um certo número de equipes de saúde da família. 
O Incentivo ao Programa de Saúde da Família...

A questão central que nos interessa aqui é a expansão do PSF, tanto aquela que se dá simultaneamente à expansão do Programa de Agentes Comunitários (PACS), como a que se dá nas áreas já anteriormente cobertas por este ${ }^{3}$.

Dentre os incentivos vigentes, enfatizamos o incentivo ao custeio do programa, mais do que as ajudas à implantação de novas equipes. Isto porque consideramos que os gestores decidem ampliar o PSF em seus municípios ponderando os problemas relativos à sustentabilidade do programa - portanto, atentos ao dimensionamento da contribuição permanente das transferências do Governo federal, não levando em conta as parcelas únicas de incentivos para a criação de novas equipes.

\section{Pressupostos Básicos de um Incentivo ao PSF: entre a expansão de cobertura dos serviços e a substituição do modelo assistencial}

A Conferência de Alma-Ata constituiu um marco no debate sobre as modalidades de cuidados de saúde e sobre as formas de se assegurar saúde para todos, num horizonte temporal não muito distante. No que se refere às modalidades de cuidados (ou melhor, de práticas) de saúde, a conferência reconheceu e enfatizou a necessidade de cuidados primários de saúde, práticas relativamente simples, de baixo custo e grande eficácia, em termos de melhoria de alguns indicadores de condições de saúde e de vida de uma pópulação.

Uma das teses centrais de Alma-Ata era que a expansão desses cuidados primários de saúde se apresentava como uma estratégia melhor que a mera expansão da oferta dos serviços tradicionais de assistência.

As razões dessa superioridade diziam respeito ao menor custo dos cuidados primários de saúde e sua grande eficácia. Parecia claro que a expansão desses cuidados seria a melhor forma de melhorar a saúde de uma população, sobretudo nos países com poucos recursos. Constituía-se, assim, a estratégia que ganhou o nome de atenção primária.

Mas Alma-Ata nunca teve uma leitura unívoca. Alguns, enfatizando as modalidades de cuidado, foram associando a expressão "atenção primária" a um conjunto limitado de práticas de baixo custo e alto impacto, aplicadas a grupos que viviam em condições de miséria, feitas sem o concurso de profissionais de nível superior (os agentes comunitários de saúde tinham participação decisiva nessas práticas) ou sem o concurso de tecnologia sofisticada. 
Contribuiu para essa construção a tese defendida pelo Unicef no início dos anos oitenta, segundo a qual muitos países ditos em desenvolvimento não teriam recursos nem mesmo para a universalização da saúde na direção que Alma-Ata indicava como básica. A partir dessa tese, o Unicef propôs "a revolução da mortalidade infantil": um esforço de difusão, nos países em desenvolvimento, de um pacote bastante seletivo de intervenções altamente eficazes em termos de custo ${ }^{4}$. Também contribuiu para essa leitura da atenção primária, como um pacote de intervenções, a noção de grupo maternoinfantil, a qual deveria ser prioritária nas políticas de saúde.

É importante que se diga que essa acepção de atenção primária foi a que mais se difundiu entre nós no Brasil. Na medida em que se foi consolidando, nos anos oitenta, o ideal societário de uma visão universalista e igualitária do direito de acesso aos serviços de saúde, surgiram muitas críticas a essa visão de atenção primária, associada à intenção de oferecer atenção precária aos mais pobres.

$\mathrm{Na}$ medida em que as transformações demográfico-epidemiológicas foram se tornando mais nítidas, cresceram as dúvidas acerca do alcance e impacto da prática da atenção primária de saúde, tal como pensada no início dos anos oitenta. Ao mesmo tempo em que se constituía essa leitura, que identificava atenção primária com um conjunto limitado de intervenções de baixo custo, outros seguiram enfatizando a dimensão estratégica da atenção primária, vendo na expansão dos cuidados primários de saúde um modo de induzir a transformação dos sistemas de saúde.

Nessa segunda perspectiva, a expansão dos cuidados primários de saúdé não poderia ser dissociada da ampliação do sistema de serviços de saúde como um todo, e da reorganização dos demais serviços de saúde de forma mais adequada às necessidades da população. Isso porque a estratégia de atenção primária asseguraria o acesso aos cuidados de saúde mais freqüentemente necessários, redimensionando também a demanda para os níveis mais complexos (e onerosos) do sistema. Assim, a prática dos cuidados primários de saúde deveria ser associada ao acesso à rede hierarquizada de serviços de saúde.

Grosso modo, a segunda acepção de atenção primária como estratégia de transformação do sistema de saúde escapa das críticas desferidas contra a atenção primária na primeira acepção. Ao enfatizar a importância do primeiro nível de atenção e sua capacidade de dar respostas aos problemas de saúde mais freqüentes, abre-se a possibilidade de recompor continuamente os recursos tecnológicos do primeiro nível de atenção, ampliando sua 
definição e campo de atuação para além de um pacote limitado de ações. Como parte do sistema de serviços de saúde, esse nível básico de atenção segue as mesmas diretrizes e princípios do sistema como um todo. No caso brasileiro, ele deve ser um modo de assegurar o acesso universal e igualitário a todos os serviços de saúde necessários à promoção, prevenção e recuperação da saúde, oferecendo esses serviços e viabilizando o acesso nos outros níveis da rede de serviços de saúde.

Nessa acepção transformada de atenção primária, como estratégia de mudança do sistema de saúde, aceita-se a tese de que a expansão da cobertura aos grupos excluídos possa se fazer, primeiramente, através de cuidados mais simples e de custo mais baixo, mas apenas como etapa provisória de expansão, que permite maximizar impactos epidemiológicos na acentuada escassez de recursos. Por sua vez, a segunda perspectiva preserva a ênfase na expansão da cobertura do sistema de saúde como um todo, ou seja, a perspectiva de inclusão gradual dos grupos socialmente mais frágeis.

Entre nós, o predomínio da primeira acepção de atenção primária e as críticas a ela dirigidas levaram a um certo abandono da expressão. Mesmo os que vêem a segunda acepção com simpatia, preferem expressá-la sem falar em atenção primária. Contudo, isso não anula a existência de modalidades de cuidados primários de saúde distintas, que incluem o uso de formas mais simplificadas de cuidados em grupos menos favorecidos ou em caráter emergencial.

O governo brasileiro adota essas modalidades, bem como pacotes mínimos de atenção, voltados para as regiões de seca, além de promover a atuação de agentes comunitários nas regiões em que ainda não se implantou o PSF. Cabe aceitá-las apenas como estratégias provisórias de expansão de cobertura do sistema de saúde, que em alguns casos podem ter um certo poder de indução de outros modos mais complexos de organização da atenção básica.

Esse recuo a um velho debate nos permite apreender melhor algumas das questões e inovações do PSF que incidem sobre os modelos e alternativas de seu financiamento. A primeira questão diz respeito à relação entre o PSF e o Programa de Agentes Comunitários de Saúde (PACS). A figura do agente comunitário esteve presente na quase totalidade das propostas dos cuidados primários de saúde. No contexto da atenção primária, os agentes comunitários seriam membros de uma comunidade treinados para executar muitas intervenções simples de modo resolutivo. 
Duas vantagens básicas são evocadas para justificar o trabalho dos agentes comunitários. A primeira se refere a sua maior proximidade com a cultura da população-alvo com a qual interage e à realidade das condições de vida dessa população. Supõe-se que isso conferisse maior eficácia e adequação das ações de promoção ao contexto local. Tal vantagem só se verifica, entretanto, quando os demais profissionais de saúde (sobretudo o enfermeiro e o médico) apresentam uma distância cultural da comunidade no qual atuam. A segunda vantagem dos agentes comunitários no contexto da política oficial da atenção primária é sua baixa remuneração, quando confrontada com a dos demais profissionais de saúde 5 .

Em que pese a crítica da insuficiência de uma proposta de expansão de serviços de saúde através de agentes comunitários, essa estratégia tem grande eficácia na redução da mortalidade infantil e melhoria de alguns indicadores de saúde em grupos que vivem em péssimas condições de vida. Em 1991, o Ministério da Saúde criou o PACS e passou a apoiar iniciativas dessa natureza. Com maior apoio institucional do Governo federal e de alguns estados da federação, o PACS mostrou ter grande impacto sobre a mortalidade infantil em alguns estados, como na experiência do Ceará.

De certo modo, o PSF nasceu em decorrência desse sucesso do PACS, mas também em decorrência da percepção de que a ação isolada dos agentes comunitários não poderia dar respostas adequadas às necessidades de saúde que se colocavam para o primeiro nível de atenção do SUS.

A proposta do PSF, desde seu início, foi pensada em torno do princípio da integralidade, ou seja, com o sentido de articular as ações de promoção, de prevenção e assistenciais ${ }^{6}$. A composição interdisciplinar da equipe, ao contrário de algumas experiências similares centradas no médico de família, também parecia ser, pelo menos no plano discursivo, uma proposta inovadora. No fundo, sugeriam-se novas práticas de saúde, com a incorporação do agente comunitário na equipe de saúde da família.

Para o Governo federal e os estados da federação, o PACS é hoje articulado ao PSF. Mas persistem os dois programas, com dispositivos de financiamento distintos, sendo, ainda hoje, a cobertura do PACS muito maior do que a do PSF. Em parte, isso se deve ao reconhecimento de que o PACS pode ser um primeiro momento de expansão da cobertura do sistema de saúde junto a grupos excluídos. Idealmente, na medida em que se criassem as equipes do PSF, as coberturas do PACS e do PSF deveriam se igualar ${ }^{7}$.

A história do PSF pode ser dividida em dois períodos: um primeiro, que vai desde a sua criação até 1996 , no qual ele era visto predominantemente 
O Incentivo ao Programa de Saúde da Família...

como uma estratégia de expansão de cobertura do acesso aos serviços de saúde; e um segundo, a partir de 1996, no qual é considerado uma estratégia de transformação do modelo assistencial, com a pretensão de substituir as práticas tradicionais de atenção básica. Importa destacar de imediato que as decisões do Governo federal sobre o incentivo ao PSF correspondem ao segundo período.

No momento de criação do PSF, podemos afirmar com segurança que predominava, no Governo federal, a preocupaçāo com a expansão da cobertura e com as comunidades mais carentes ${ }^{8}$. A isso, acrescente-se a associação do PACS e do PSF a programas federais, como o Programa Comunidade Solidária, o Amazônia Solidária e o de Redução da Mortalidade Infantil. Em conjunto, tais prioridades têm suscitado muitas críticas ao PSF, que é classificado por alguns como parte das políticas focalizadoras do Governo federal.

Ao menos no discurso, o PSF sempre foi pensado de forma articulada ao restante do SUS. Portanto, um dos eixos do programa é a expansão gradual do acesso aos serviços de saúde. Nos primeiros anos do PSF, essa concepção pareceu predominar no posicionamento do Governo federal. Os dispositivos de apoio financeiro ao PSF guardaram, no período inicial, relação com tal preocupação, não tendo sido desenvolvidos dispositivos específicos para superar o apoio definido em bases conveniais.

Em meados dos anos noventa, a postura do Governo federal foi revista, juntamente com a mudança da vinculação institucional do programa, que passou para a responsabilidade da Secretaria de Assistência à Saúde (SAS). Surgiu aí a idéia de implantar o PSF como uma estratégia de mudança do modelo de atenção básica. Passou-se a enfatizar o "caráter substitutivo das práticas tradicionais das unidades básicas de saúde..." (Brasil, 1997, anexo 2). Na voz de formuladores dessa revisão, reconhecer o caráter substitutivo do PSF tinha implicações técnicas e políticas.

\footnotetext{
"Tecnicamente, a unidade de saúde da família passa a ser a porta de entrada do sistema, com a oferta de uma atuação sanitária que incorpora a atenção médica tradicional a uma lógica efetivamente de promoçāo à saúde" (Levcovitz e Garrido, 1996, p. 4).
}

Nessa perspectiva, o PSF supera sua formulação, limitada ao âmbito da expansão da cobertura dos serviços, para ser pensado como um modo de organizar a rede básica. Mais do que a criação de um novo tipo de unidade, tratava-se de uma proposta de reorganização das unidades básicas. 
Caberia adicionalmente destacar que, ao se colocar o PSF como modo de organização da atenção básica e porta de entrada para o SUS, estendese o campo de abrangência das ações para o universo da população. Essa extensão implica uma mudança no juízo normativo sobre a proposta do PSF, que não mais é percebida como proposta provisória e parte de um processo de expansão da oferta dos serviços de saúde, mas como a melhor estratégia de atenção básica.

A cobertura do PSF passa a ser o principal parâmetro de acompanhamento, pois idealmente ela deve chegar perto de $100 \%$. Note-se que, na perspectiva anterior, bastava que as coberturas do PSF e do PACS fossem idênticas e que todos os cidadãos brasileiros tivessem acesso ao nível de atenção básica, quer através do PSF, quer através de outras modalidades. Naquela concepção, o PSF poderia ser entendido como uma modalidade adequada a algumas regiões, localidades ou grupos sociais, mas não necessariamente a todas.

A partir de 1996, essa visão é posta em xeque pelo próprio Governo federal, uma vez que as experiências com o PSF, embora restritas a algumas localidades, já indicavam o grande potencial do programa. Diziam os formuladores:

"O aspecto político-administrativo da substituição deve ser impulsionado em breve, com a edição da NOB 96. Como já temos exemplos suficientes das possibilidades do PSF, [...] a norma vai tratar de valorizar o empenho político de investimento do gestor municipal. Assim, não seremos nós do Ministério da Saúde a aconselhar comedimento. Muito pelo contrário, vamos apoiar quem queira entrar de fato na reorganização da sua atenção básica. A NOB 96 valoriza o incremento da cobertura, quanto mais áreas atendidas [pelo PSF], maior o incentivo financeiro" (Levcovitz e Garrido, 1996, p. 4).

Esse trecho decodifica a lógica política que presidiu a iniciativa da criação do incentivo ao PSF. Sendo evidentes os benefícios do PSF, o Governo federal decide apoiar os gestores que, sensíveis às evidências, resolvam adotar de fato as "best practices" recomendadas, adotando o PSF como forma de substituir suas práticas tradicionais de atenção básica. Ou seja, reforça-se a adesão às idéias com a criação de um incentivo financeiro proporcional à cobertura do PSF.

Contudo, não se tratava de uma posição fundamentalista, por duas razões que merecem ser destacadas. A primeira diz respeito a uma salvaguarda dada pelos próprios formuladores: 
O Incentivo ao Programa de Saúde da Família...

"este empenho substitutivista, entretanto, não significa que se esteja apontando para o extermínio das outras modalidades de atenção ambulatorial. Não se trata de substituição nesse sentido fundamentalista, mas de proposição de um novo eixo estruturante" (Levcovitz e Garrido, 1996, p. 4).

A segunda razão, exposta pelos mesmos autores, é a seguinte:

“Assim, serāo os próprios municípios que deverão planejar a implementação e expansão de suas equipes, atentos às suas realidades e possibilidades locais. Municípios como Curitiba e Londrina [...] têm um acercamento mais nítido de suas necessidades em torno de $30 \%$ de cobertura de sua população com - PSF. Já Camaragibe, Brumadinho e Campina Grande, vão de $70 \%$ até mesmo à quase totalidade de suas populaçōes. Possivelmente, estão todas certas. É esse o horizonte de substituição que está sendo intentado: a definição e a opção por uma forma de prestação de serviços que valorize o vínculo, que se integre no sistema local de saúde e que assuma responsabilidades. E responsabilidade e vínculo não se garantem por decreto" (Levcovitz e Garrido, 1996, p. 4).

$\mathrm{O}$ texto acima, escrito antes da implementação dos dispositivos de incentivo ao PSF, retrata os dilemas que ainda rondam as discussões sobre o financiamento do PSF. Com efeito, há uma tensão entre duas posições. De um lado, a confiança na superioridade universal do PSF frente a outras modalidades de organização da atenção básica, que se associa a uma imagem-objetivo de um nível de cobertura de $100 \%$ do PSF e que desemboca em incentivos proporcionais à cobertura. De outro, uma aposta na superioridade da avaliação local para estabelecer os ideais (também locais) de cobertura do PSF, no contexto de seus projetos de (re)organização da rede básica e do sistema como um todo.

Não é difícil mostrar como a primeira posição tem predominado nos dispositivos de incentivo ao PSF adotados pelo Governo federal. Tal predomínio precisa ser contextualizado: no momento da discussão da NOB 96, ainda eram poucos os municípios que assumiam de fato a gestão do sistema. Uma das virtudes dessa NOB foi ter permitido que praticamente todos os municípios brasileiros se habilitassem em uma das duas modalidades de gestão, passando a receber diretamente os recursos transferidos pelo Ministério da Saúde correspondentes ao respectivo nível de habilitação (Levcovitz et al., 2001). Antes que tal realidade se configurasse, seria efetivamente temerário afirmar de modo categórico a 
superioridade do juízo local acerca da cobertura ideal do PSF numa certa cidade.

Gostaríamos de reiterar que as idéias de um incentivo ao PSF que tomasse como parâmetro chave a cobertura do programa, premiando assim o esforço dos gestores de reorganização da atenção básica, nasceram no contexto da discussão da NOB $96^{9}$.

Ao criar o Piso de Atenção Básica (PAB) como forma de transferência per capita, e não baseada na produção de serviços, a NOB 96 deu início a um processo gradual de mudança na lógica que preside as transferências do gestor federal para os gestores dos demais níveis de gestão. $\mathrm{O} \mathrm{PAB}$ podia oscilar numa faixa entre $\mathrm{R} \$ 10,00$ a $\mathrm{R} \$ 18,00$ por habitante por ano. $\mathrm{O}$ valor de $\mathrm{R} \$ 10,00$ foi calculado tendo por base a série histórica do valor dos pagamentos feitos pelo ministério aos serviços de atenção 'básica, mas seu impacto foi diferente sobre diferentes municípios. Em termos gerais, ele homogeneizou um patamar mínimo de recursos per capita disponibilizados para a atenção básica, o que beneficiou diretamente muitos municípios (os que anteriormente não gastavam anualmente $\mathrm{R} \$ 10,00$ por habitante na atenção básica).

Além da criação do $\mathrm{PAB}$, a NOB 96 criou o PAB variável, conjunto de incentivos a alguns programas específicos, repassados diretamente aos municípios habilitados, condicionados a alguns requisitos estabelecidos através de portarias específicas e avaliados pela respectiva Comissão Intergestores Bipartite (CIB). É aqui que se alojou o incentivo ao PSF, assim como ao PACS. O incentivo do PSF (assim como o do PACS) tem passado por algumas modificações desde então, mas vem seguindo a mesma lógica geral.

Note-se que, nesse arranjo, independentemente dos critérios operacionais de cálculo do valor dos incentivos do PAB variável, a atenção básica tem duas formas de transferência do Governo federal para os municípios. O PAB fixo auxilia o custeio de todas as ações da atenção, quaisquer que sejam as modalidades de organização dessa atenção à saúde. Os gestores que resolveram implementar o PACS /PSF em suas cidades têm, adicionalmente, um incentivo através do PAB variável. Sendo assim, na medida em que o caráter substitutivo do PSF frente às demais práticas de atenção básica se manifeste mais amplamente, o PSF passa a contar tanto com os valores do incentivo do PAB variável quanto do $\mathrm{PAB}$ fixo, para auxiliar seu custeio. Esse arranjo por si só incentiva o caráter substitutivo do PSF. Ou seja, ele cria indiretamente uma primeira dimensão de ênfase na cobertura do PSF/PACS. 
Em síntese, o PSF, concebido como uma modalidade de atenção básica que deveria expandir-se progressivamente, substituindo, por incorporação, as práticas de atenção básica dos agentes comunitários, passou a ser concebido como modalidade de atenção básica que deveria expandir-se substituindo, através de um processo de reorganização, as demais modalidades da atenção básica. É claro que cada município deveria, na medida em que assumisse as responsabilidades do gestor, pelo menos da sua rede básica, estabelecer qual seria o ritmo de expansão do PSF e do PACS, bem como ajuizar o nível de cobertura ideal desses programas no seu município. Os incentivos do PACS e do PSF, entretanto, foram construídos para valorizar o empenho dos gestores nesse esforço de reorganização da atenção básica. Ou seja, o Ministério da Saúde, como defensor do caráter universal do PSF, não aconselha o comedimento dos gestores municipais nesse empreendimento de reforma da rede básica e introduz dispositivos de cálculo que fortemente valorizam a cobertura do programa, muito além daquela valorização indireta que já mencionamos.

São esses dispositivos que passaremos a examinar com mais detalhe. Antes, porém, é necessário justificar a ênfase que aqui daremos ao incentivo do PSF, em detrimento do incentivo do PACS.

Desde a perspectiva de reorganização da atenção básica, é o PSF (incluindo os agentes comunitários vinculados às equipes) que se afirma como proposta inovadora, e não o PACS sem $\operatorname{PSF}^{6}$.

\section{Uma Análise dos Dispositivos de Cálculo do Incentivo do PSF}

Vimos que o incentivo do Governo federal ao PSF foi concebido como forma de promover a expansão do PSF não apenas aos grupos postergados, mas ao universo da população. Desde o primeiro momento, pensou-se em privilegiar os gestores que se esforçavam por ampliar a cobertura do PSF. Assim, a idéia era de um incentivo financeiro que variasse em função da cobertura do programa: quanto maior a cobertura, maior o incentivo.

Entretanto, várias propostas de formas de cálculo desse incentivo foram formuladas. Analisaremos aqui apenas a da Portaria n. 1.329 , de 12 de dezembro de 1999 , ainda em vigor.

Como hipótese de trabalho, consideramos que um gestor municipal, diante da tarefa de desenhar o projeto do PSF de seu município, sobretudo para definir a cobertura possível, leva em conta tanto o adicional de recursos anuais transferidos pelo Governo federal que obterá em conseqüência da 
implantação de tantas equipes do PSF, como o grau de participação desses recursos no custeio do programa. São, portanto, duas as dimensões do incentivo apreciadas pelos gestores.

Um bom parâmetro para apreciar a primeira dessas dimensões - relativa ao montante geral de recursos transferidos pelo Governo federal em virtude do PSF - em municípios de populações diferentes é o valor do incentivo por habitante. Um parâmetro que poderia ser útil para analisarmos a segunda dimensão - o grau de participação do Governo federal no custeio do PSF - é o valor do incentivo por habitante coberto pelo programa. Como pretendemos examinar as questões relativas ao impacto diferenciado do incentivo nas cidades mais populosas, tentaremos analisar essas duas dimensões utilizando, na medida do possível, tais parâmetros.

\section{Variações do Incentivo do PSF por Habitante em Função da Cober- tura}

Como o valor do incentivo por habitante varia em função da cobertura? Há diferenças nessas variações entre os municípios com populações diferentes? Para responder a essas perguntas, buscamos construir a curva do valor do incentivo por habitante em função da cobertura do $\mathrm{PSF}^{11}$.

O tipo de curvas utilizada nesta seção permite que, dada a cobertura do PSF num município, possamos conhecer qual o valor per capita do incentivo do PSF naquele município. Analogamente, a curva nos permite identificar qual a cobertura do PSF necessária para se obter um acréscimo anual de $x$ reais por habitante por ano nas transferências do Governo federal.

Segundo o critério da Portaria n. 1.329, o incentivo do PSF consiste em transferir um valor fixo por cada equipe de PSF existente num município. Foram estabelecidas diferentes faixas de remuneração por equipe, em função da cobertura do PSF. Assim, o valor anual que um certo município recebe por cada equipe é dado pelo quadro 1 .

Por exemplo, um município com $50 \%$ de sua população cobertos pelo $\mathrm{PSF}$, receberia anualmente um total de $\mathrm{R} \$ 47.166,00$ por cada equipe do PSF existente ${ }^{12}$.

O valor total que um município recebe como incentivo é dado pela fórmula

$$
\text { Valor total }=\mathrm{E} \times \mathrm{V}
$$

onde (E) equivale ao número de equipes de saúde da família no município 
O Incentivo ao Programa de Saúde da Família...

e (V) é o valor pago por equipe, ainda segundo o quadro 1. Assim, o valor do incentivo por habitante seria expresso pela fórmula

$$
\text { Valor per capita }=\frac{\mathrm{E} \times \mathrm{V}}{\mathrm{P}} \text {, }
$$

onde $\mathrm{P}$ é a população total do município.

Essa equação, contudo, ainda não nos oferece a possibilidade de apreender a variação do incentivo per capita em função da cobertura do programa. Para tal, precisamos estabelecer a relação, para um município com população $(\mathrm{P})$, entre o número de equipes $(\mathrm{E})$ e o grau de cobertura do programa. Isso nos remete à discussão dos parâmetros de cobertura de uma equipe de saúde da família.

O texto da Portaria n. 1.886, de 18 de dezembro de 1997, que estabeleceu as diretrizes para o PACS e para o PSF, definia que cada equipe de saúde da família deveria se responsabilizar por mil famílias, ou 4.500 pessoas. Tacitamente, admitia-se uma média de 4,5 pessoas por domicílio, uma média efetivamente mais alta do que a real. Entretanto, desde os primeiros documentos do PSF já se admitia que a quantidade de famílias acompanhadas por uma equipe de saúde variaria entre 800 e mil, em função da densidade demográfica e das condições de deslocamento de cada localidade.

A Portaria n. 157, de 1998, reconheceu essa variação, definindo que cada equipe acompanharia no mínimo 2.400 pessoas e no máximo 4.500 . Tacitamente, esse valor mínimo corresponderia a 800 famílias, com média de três pessoas por domicílio. De qualquer forma, o número cabalístico para cálculos de média passou a ser a média desses dois valores de certo modo arbitrários, ou seja, 3.450 pessoas por equipe.

Embora um tanto arbitrários, esses números não são incoerentes. Segundo os dados do IBGE, a média de pessoas por domicílio é 3,5, de modo que se cada equipe acompanhasse em média mil famílias, acompanharia cerca de 3.500 pessoas, valor muito próximo ao cabalístico 3.450 .

Consideramos, no raciocínio a seguir, que cada equipe de saúde se responsabiliza por 3.450 habitantes ${ }^{13}$. Ora, se uma equipe abrange 3.450 pessoas, o número de equipes de um município será equivalente a

$$
\mathrm{E}=\underline{\mathrm{P} \text { coberta pelo PSF }}
$$

3.450

Mas se nos for dada a cobertura do PSF (C), expressa em centésimos, 
então a população coberta pelo programa seria $(\mathrm{PxC})$ e o número de equipes seria

$$
\mathrm{E}=\frac{\mathrm{C} \times \mathrm{P}}{3.450}
$$

Aplicando a última equação na fórmula do valor do incentivo per capita, teríamos

$$
\text { Valor per capita }=\frac{\mathrm{C} \times \mathrm{P} \times \mathrm{V}}{3.450 \times \mathrm{P}},
$$

Ou, simplificando:

$$
\text { Valor per capita }=\frac{\mathrm{C} \times \mathrm{V}}{3.450}
$$

Note-se que, se (V) fosse constante, o valor do incentivo per capita por habitante variaria linearmente em função da cobertura. Isso significa que, se $o$ incentivo fosse definido como o repasse de um certo valor fixo, único para todos os municípios, o valor desse incentivo expresso em reais por habitante cresceria proporcionalmente à elevação da cobertura. Contudo, isso não sucede, pois a portaria estabelece valores (V) distintos para cada uma das faixas de cobertura apresentadas anteriormente. O gráfico 1 sintetiza a variação do valor per capita do incentivo em função da cobertura de acordo com esse critério atual. Mostra que todo município que alcançar $100 \%$ de cobertura do PSF receberá anualmente pouco menos de dezesseis reais por habitante (além do PAB fixo e do incentivo do PACS).

O critério atual, da Portaria n. 1.329, mantém uma idéia que já estava presente na proposta da NOB 96: a de realizar acréscimos maiores do valor per capita do incentivo por um mesmo ganho de cobertura do programa nas faixas de cobertura mais elevadas. Como vimos, para cada valor de remuneração por equipe de saúde da família, os valores per capita do incentivo crescem linearmente em função da cobertura. O que a Portaria n. $1.329 \mathrm{faz}$ é, nos limites das faixas de cobertura estabelecidas, "saltar" de uma reta para outra. O gráfico 2 ilustra esse "movimento", ao superpor a curva gerada pelo critério vigente às curvas hipotéticas que seriam geradas se fixássemos os valores do incentivo por equipe de saúde da família. (No gráfico, utilizamos os mesmos valores adotados para as faixas de cobertura da portaria).

Note-se que, nesse critério, as coberturas mais altas do PSF são tripla- 
O Incentivo ao Programa de Saúde da Família...

mente valorizadas. Em primeiro lugar, porque, para qualquer valor fixado de incentivo por equipe de saúde, o valor per capita adicionado (e, obviamente, o montante de recursos transferidos ao município) cresce continuamente com o aumento das coberturas. Em segundo, porque, adicionalmente, nas maiores faixas de cobertura, incrementa-se o acréscimo per capita para um mesmo acréscimo de cobertura. Além das duas formas diretas de valorização, aplica-se aqui ainda a terceira forma, pois quanto mais elevada é a cobertura, na perspectiva de substituição do modelo de atenção básica, maior proporção do PAB fixo é destinada adicionalmente às ações básicas realizadas pelo PSF.

Quando consideramos a primeira dimensão do incentivo do PSF — a que se refere ao volume per capita de recursos federais que passam a ser transferidos para o gestor municipal que implante ou amplie o PSF no seu município - e analisamos o critério de cálculo vigente, podemos extrair algumas conclusões.

O primeiro ponto a destacar é que os valores per capita do incentivo alcançados por um certo grau de cobertura são independentes da população da cidade. Isso significa que um gestor do sistema de saúde de uma grande cidade receberá exatamente o mesmo valor per capita de incentivo que um gestor de um pequeno município com mesmo grau de cobertura do PSF. É claro que, em termos de volume global de transferências do incentivo, as grandes cidades receberão um volume consideravelmente maior.

O segundo ponto é que o critério atual estabelece um duplo dispositivo de valorização da cobertura do PSF: além de estabelecer um valor por equipe, o que por si só, como vimos, já se constitui num incentivo à ampliação da cobertura (no que se refere à primeira dimensão que ora analisamos), ele faz esse valor por equipe variar em função de faixas de cobertura.

\section{Sobre a Contribuição do Incentivo sobre o Custeio do Programa}

No que diz respeito à primeira dimensão do incentivo, relacionada ao montante dos recursos adicionais transferidos pelo Governo federal em decorrência da implantação ou expansão do PSF, o critério atual corresponde aos anseios dos primeiros formuladores, de valorizar o esforço dos gestores na ampliação do PSF e na substituição do modelo de atenção básica. Mas, e quanto à segunda dimensão, relativa à contribuição do governo no custeio do PSF?

Parâmetro que pode nos ajudar a pensar sobre essas questões é o custo 
do programa por habitante coberto. Trata-se, entretanto, de informação muito difícil de ser obtida. De fato, temos ainda muita dificuldade para obter dados comparativos e abrangentes sobre os custos de diferentes modalidades de atenção e da participação dos recursos próprios e das transferências de outros níveis de governo nesse custeio.

Um caminho que pode ser seguido é o da estimativa das despesas de pessoal da equipe de saúde da família. Os salários dos profissionais variam muito de uma localidade para outra, tendendo a ser mais elevados do que os salários dos demais profissionais da área de saúde. Essa elevação salarial parece ser fundamental para atrair profissionais, sobretudo médicos, que em geral não colocam a perspectiva de atuar numa equipe de saúde da família como ideal profissional.

De qualquer modo, um exercício simples pode dar idéia da ordem de despesas por habitante coberto, estimada em cerca de vinte reais/ano ${ }^{14}$. Tal estimativa, sem dúvida subestimada, serve para indicar que o Governo federal nāo pretende, com o incentivo, custear integralmente os salários e encargos do PSF, mas que participa em certo grau desse custeio. Ora, o valor máximo pago pelo Governo federal, no caso de municípios com cobertura maior que $70 \%$, é de $\mathrm{R} \$ 54.000,00$, que (supondo que uma equipe atenda a 3.450 pessoas) equivale a $\mathrm{R} \$ 15,65$ por pessoa coberta ao ano.

Para nossos propósitos, mais importante do que a difícil tarefa de estimar os custos do PSF por pessoa cobertá, é analisar as conseqüências dos critérios de cálculo do incentivo do PSF sobre a magnitude da participação desse incentivo no custeio do programa. Ao se definir um valor fixo por equipe de saúde da família, fixa-se simultaneamente um valor por pessoa coberta para tal incentivo. Em outros termos, se o critério vigente definisse um mesmo valor por equipe para todos os níveis de cobertura, o montante geral e o volume de recursos por habitante continuariam aumentando em função da cobertura, mas a contribuição do incentivo no custeio das equipes seria constante, independentemente do grau de cobertura.

Não é esse o caso do critério atual, o da Portaria n. 1.329. Aqui, a contribuição do incentivo por pessoa coberta varia de $\mathrm{R} \$ 8,12$ a $\mathrm{R} \$ 15,65$. Este é o significado dos "saltos" entre diversas retas ilustradas no gráfico 2. Cada reta representa um certo valor fixo de contribuição do incentivo por habitante coberto pelo programa. O quadro 2 mostra esses valores de incentivo por habitante coberto para cada uma das faixas de cobertura definidas na Portaria n. 1.329, calculados com o parâmetro de 3.450 pessoas por equipe. Como um município pode adotar outro parâmetro de cobertura den- 
tro da faixa de 2.400 e 4.500 pessoas por equipe, calculamos também os valores para esses parâmetros limites. Note-se que a contribuição do incentivo ao custeio das equipes varia em função dos parâmetros de cobertura de uma equipe de saúde da família. Municípios em regiões de baixa densidade demográfica que adotem o parâmetro mínimo de 2.400 habitantes por equipe têm maior aporte das transferências federais no custeio de suas equipes.

É exatamente frente à questão do peso diferencial da contribuição do incentivo do Governo federal no custeio das equipes em função da cobertura que pode ser levantada uma crítica ao alcance do incentivo, no que diz respeito às grandes cidades. Com efeito, nas cidades com maior número de habitantes, é necessário um número maior de equipes para que se atinja o mesmo grau de cobertura. Portanto, há que se implantar um grande número de equipes para se alcançar as coberturas que incrementam os valores da contribuição do Governo federal por habitante coberto. O quadro 3 ilustra bem a situação: apresenta o número de equipes de saúde da família com que um município, com certa população, alcança a faixa de cobertura superior e, portanto, eleva o patamar da contribuição do incentivo no custeio de suas equipes.

Esse quadro, ao mostrar com quantas equipes municípios com certas populações passam a receber um certo valor do incentivo por equipe, permite pôr em evidência vários aspectos do critério vigente. Pode-se notar, inicialmente, que a primeira faixa, que remunera $R \$ 28.008,00$ por equipe, só vige para cidades relativamente grandes, pois as médias ou pequenas já atingem a faixa de remuneração imediatamente superior com apenas uma equipe de saúde da família. Toda cidade com menos de 70 mil habitantes, ao criar sua primeira equipe, já terá ultrapassado a primeira faixa (e muitas pequenas cidades já terão avançado muitas faixas). Por outro lado, um município como o Rio de Janeiro teria de criar mais de 70 equipes antes de "saltar" para nova faixa de remuneração, granjeando deste modo um adicional de R\$ 0,78 por habitante coberto por ano $^{15}$, e São Paulo, mais de 140 equipes.

Analogamente, para chegar à mais elevada faixa de remuneração por equipe, uma cidade com 100 mil habitantes precisa criar sua vigésimaprimeira equipe, enquanto um município de 250 mil habitantes precisa ter mais do que cinquienta equipes. E São Paulo teria que ter mais de duas mil equipes implantadas.

É compreensível que os gestores das grandes cidades, nesse contexto, não se sintam incentivados pelo Governo federal para ousar significativas 
expansões de cobertura do PSF. Eles tendem a se sentir muito menos apoiados no custeio das equipes do que os municípios pequenos.

É possível que o esforço de criar e manter centenas de equipes de saúde da família seja bastante diverso do que o esforço de criar e manter algumas poucas dezenas de equipes. De fato, temos ainda poucas experiências dessa magnitude. É razoável admitir que seja necessária e oportuna uma nova forma de incentivo específica para a expansão do PSF nas grandes cidades. É o que passaremos a explorar em seguida.

\section{Explorando Algumas Alternativas}

Pelo que vimos, o critério atual de cálculo do incentivo do PSF trata do mesmo modo todos os municípios, independentemente de sua população.

Quando consideramos o montante geral das transferências do Governo federal no componente do PAB variável destinado ao PSF, tomado em valores por habitante, vimos que o critério atual é equânime: todos os municípios têm um crescimento análogo dos incentivos per capita em função da cobertura do programa - o que é coerente com a política de incentivo da reforma da atenção básica em curso.

A menor adesão das grandes cidades ao PSF pode ter pelo menos várias razões. Entre elas, pode estar a percepção, pelos gestores, de que devem empreender um enorme esforço para implantar o PSF, alcançando algumas centenas de milhares de habitantes, mas que, ao final, ainda teriam uma cobertura baixa e, portanto, uma contribuição pequena dos recursos do Governo federal.

Quais seriam as alternativas? Seria possível construir um critério de cálculo do incentivo que ajudasse o PSF a deslanchar nas grandes cidades? Antes de responder afirmativamente, estamos já em condições de definir a tarefa: trata-se de construir um critério que permita, explícita ou implicitamente, que as grandes cidades recebam um valor por equipe mais elevado do que cidades menores, para um mesmo grau de cobertura.

A primeira alternativa para tal incentivo, aparentemente natural, consiste em tentar repartir as grandes cidades em formas de distritos ou regiões sanitárias, e aplicar as faixas de cobertura em cada um desses distritos. Para efeito da aplicação do critério, é como se uma grande cidade fosse dividida em cidades menores. Entretanto, tal divisão só se traduziria em aumento da participação do Governo federal no custeio das equipes se houvesse concentração das equipes em alguns desses distritos ou regiões. 
Imaginemos, por exemplo, um município de um milhão de habitantes, que almeje criar 60 equipes de PSF. Com elas, ele atingiria um patamar de $21 \%$ de cobertura, recebendo como incentivo pelos critérios atuais $\mathrm{R} \$ 38.520,00$ por cada equipe ao ano. Suponhamos que o município seja dividido em dez regiões de 100 mil habitantes, e que as equipes se distribuam também pelas dez regiões. Neste caso, em cada região a cobertura atingida seria dos mesmos $21 \%$ e, portanto, não haveria qualquer mudança. Mas se as 60 equipes se distribuíssem igualmente em apenas três das dez regiões, cada uma teria vinte equipes, o que daria uma cobertura de $69 \%$ e um patamar de incentivo por equipe de $\mathrm{R} \$ 50.472,00$ (é claro que, nessas condições, o gestor faria um grande esforço para criar mais uma equipe em cada região e alcançar o patamar mais alto de remuneração por equipe). Ou seja, com um mesmo número de equipes do PSF, as grandes cidades poderiam obter, conforme a maior ou menor concentração de equipes em poucas áreas, um valor do incentivo por equipe distinto.

Há várias formas de distribuir as equipes pelas regiões, cada qual com um impacto diverso no resultado de aporte do incentivo no custeio das equipes. Por exemplo, seguindo o mesmo exemplo da cidade de um milhão de habitantes, que 24 equipes se concentrem numa das dez regiões e as 36 restantes se distribuam igualmente pelas outras nove, teríamos o seguinte: na regiāo privilegiada, a cobertura seria de $82 \%$, e o município receberia $\mathrm{R} \$$ $54.000,00$ por cada uma das 24 equipes. Nas demais regiões, a cobertura seria de $13,8 \%$, de modo que cada equipe receberia do Governo federal $\mathrm{R} \$$ $33.360,00$. No conjunto, o município receberia por cada equipe, em média, $\mathrm{R} \$ 41.616,00$.

Até aqui utilizamos exemplos de subdivisões das cidades em partes com mesmo número de habitantes, situação pouco plausível. Mas o que ocorre se as subdivisões tiverem populações distintas? Nesse caso, a primeira alternativa de incentivo às grandes cidades tenderia a induzir uma concentração de equipes nas regiões menos populosas. Isso porque a criação de uma equipe em tais regiões eleva mais a cobertura do PSF do que a criação de uma equipe nas regiões com maior número de habitantes.

Portanto, se os critérios de faixa de cobertura passam a ser aplicados a subdivisões das grandes cidades, haverá maior contribuição do Governo federal, na medida em que haja uma concentração das equipes em algumas dessas regiões. Não se trata tão somente de reconhecer que a estratégia de expansão do PSF em certa localidade pode privilegiar certos grupos postergados e certas regiões que concentram os que vivem em piores condições 
de vida, como os primeiros formuladores da idéia de um incentivo admitiam. Essa forma de aplicar as faixas de cobertura incentiva a concentração de equipes, o que contradiz o propósito de substituir as modalidades de atenção básica tradicionais. Note-se que, se um gestor logra obter $70 \%$ de cobertura em uma região de sua cidade, o custo de implantação de mais equipes na região já amplamente coberta será menor do que o custo de implantação de uma nova equipe em qualquer outra região com menor cobertura.

Agregue-se a isso outra conseqüência de um tipo de ajuste. O critério da Portaria n. 1.329 tem como uma de suas virtudes a clareza das regras. Todos os gestores municipais sabem quanto eles e os outros receberão do Governo federal por equipe do PSF. Caso a aplicação nas grandes cidades passe a se fazer por subdivisões da mesma, o valor médio de incentivo por equipe dos grandes municípios passa a depender significativamente da distribuição das equipes pelas diversas subdivisões. A análise do resultado final por outros gestores fica mais difícil, o que pode trazer problemas nos fóruns das CIBs. Não é simples explicar a razão pela qual dois municípios com a mesma população e o mesmo número de equipes do PSF deveriam receber incentivos diferentes por equipe.

Por essas razões, somos levados a defender que a aplicação das faixas de cobertura siga levando em conta a cobertura do PSF no município como um todo, e não nas subdivisões das grandes cidades.

Uma segunda alternativa de mudança no critério do cálculo do incentivo, concebida para aumentar sua eficácia junto às grandes cidades, consiste em, reconhecendo-se que o esforço da criação e expansão de equipes nessas grandes cidades é de patamar distinto do das cidades menores, criar explicitamente uma diferenciação para os municípios mais populosos. A proposta da qual tratamos agora seria uma diferenciação no valor pago por equipe para os municípios que tiverem atingido um certo número de equipes implantadas.

Há várias possibilidades de desenhos operacionais para tal incentivo. Se aceitarmos que a criação e manutenção de um certo número de equipes acima de determinado patamar (digamos, $\mathrm{X}$ equipes) é bem mais complexa, a ponto de justificar maior apoio do Governo federal no custeio das equipes, então se poderia introduzir uma mudança no valor de incentivo por equipes para os municípios que tivessem mais do que $\mathrm{X}$ equipes.

Por exemplo, vamos analisar a seguinte proposta: os municípios que constituírem cem ou mais equipes passarão a receber como incentivo o valor de $\mathrm{R} \$ 54.000,00$ por equipe ao ano, independentemente da cobertura 
alcançada. A regra é bastante simples e se superpōe aos critérios atuais, embora suas conseqüências mereçam exame mais detalhado.

Quem se beneficiaria com esse critério? As cidades que com cem equipes ainda não atingiram um patamar de $70 \%$ de cobertura. Com a ajuda do quadro 3, podemos ver que as cidades com 500 mil habitantes ou mais seriam as únicas a ter algum benefício. Isto porque as cidades com populações menores ou nunca necessitariam de cem equipes de PSF, ou, ao constituir cem equipes, já teriam alcançado a faixa de maior remuneração por equipe. Mas do que isso, o benefício, e portanto o incentivo, seriam tão maiores quanto maior fosse a cidade. Assim, ainda com auxílio do quadro 3 , podemos ver que um município de 750 mil habitantes, que com cem equipes teria um incentivo por equipe de $R \$ 44.100,00$, teria com a adição desse novo critério um acréscimo de $\mathrm{R} \$ 9.900,00$ por equipe ao ano; um de um milhão, um acréscimo de $R \$ 12.780,00$ ao ano, e o município de São Paulo, com seus mais de dez milhões de habitantes, receberia um acréscimo de $R \$ 25.992,00$ por equipe ao ano. É um critério que decididamente (e, nesta forma, radicalmente) valoriza o esforço dos gestores das grandes cidades, no sentido de instituir um novo patamar de experiências de cidades com grandes números de equipes de saúde da família.

Por outro lado, nas grandes cidades, o critério proposto não modifica os princípios básicos que têm norteado a discussão do incentivo do PSF desde o debate da NOB 96: o valor do incentivo per capita continua crescendo em função da cobertura.

Como exemplo, sugerimos anteriormente um patamar de cem equipes para a instituição de um novo patamar de incentivo por equipe, e sugerimos que esse valor fosse o mais elevado segundo o critério vigente. É claro que outras propostas de patamar e de valores por equipe poderiam ser exploradas.

Um primeiro conjunto de variações possíveis desse tipo de incentivo ao PSF nas grandes cidades é a definição de outros valores para o patamar de $X$ equipes, a partir do qual se modifica o valor do incentivo por equipe. Poder-se-ia definir, por exemplo, esse patamar em 50 equipes, ou em 20. Quanto menor o patamar, maior número de grandes cidades poderá ser beneficiado com o novo critério. Se o patamar para o novo valor por equipe for 50 , serão beneficiados municípios com cerca de 250 mil habitantes; se for 20 , municípios com mais de 98.571 habitantes $^{16}$. A decisão sobre o patamar sempre será política.

É possível compor um critério com várias faixas de números de equipes 
de saúde da família. Por exemplo, estabelecer que municípios com mais de 20 equipes e menos de cem, cuja cobertura do programa seja inferior a $40 \%$, receberão $\mathrm{R} \$ 41.220,00$ por equipe ao ano, e municípios com cem ou mais equipes receberão $\mathrm{R} \$ 54.000,00$. O valor do incentivo por equipe e o número de equipes nesse tipo de critério são decisões políticas, que devem levar em consideração a disponibilidade de recursos. Não se trata, obviamente, de decisão técnica.

Uma questão operacional importante para o uso de um critério como este são os parâmetros de cobertura de uma equipe de saúde da família. A Portaria n. 1.329 estabeleceu que a cobertura que permite enquadrar um município numa das faixas de incentivo por equipe seria calculada pela fórmula

$$
C=\frac{(E \times 3.450)}{P} \times 100
$$

onde (P) é a população e (E) é o número de equipes do PSF. Esse uso da fórmula, entretanto, tendia a favorecer os municípios com extensas áreas rurais, de baixa densidade demográfica, que optassem por trabalhar com os parâmetros mínimos de cobertura de uma equipe - a saber, 2.400 pessoas por equipe. Nesses casos, a cobertura estimada pela fórmula seria mais elevada do que a real, pois a população coberta, que de fato seria $\mathrm{E} \times 2.400$, era tomada como sendo $\mathrm{E} \times 3.450$. Esse problema foi resolvido com a Portaria n. 1.013 , de 8 de setembro de 2000 , que definiu que, a partir de fevereiro de 2001, as coberturas dos municípios que servem para o enquadramento nas faixas de incentivo por equipe passariam a ser obtidas diretamente a partir do número de pessoas cadastradas. É claro que os municípios que adotem o critério de 2.400 habitantes por equipe, que agora não mais contam com a antiga superestimativa de sua cobertura, ainda se beneficiam por receber um montante maior de recursos, devido ao maior número de equipes implantadas para uma mesma população efețivamente coberta.

Caso se instituísse um incentivo como o aqui proposto, com um patamar de equipes a partir do qual se eleva o valor do incentivo por equipe, talvez coubesse estabelecer alguma norma diferenciada para os parâmetros de cobertura por equipe. Se o incentivo se volta para as grandes cidades, nas quais a baixa densidade demográfica e a dificuldade de deslocamento dos membros das equipes não são características freqüentes, talvez não faça 
sentido admitir um patamar tão baixo de cobertura por equipe como 2.400 . Caso contrário, gestores de algumas grandes cidades poderiam adotar os parâmetros menores e alcançar o patamar que Ihes concede elevação da remuneração por equipe. Em parte, isso pode ser evitado por um procedimento análogo ao da Portaria n. 1.013: em vez de dizer "os municípios que tiverem implantado $\mathrm{X}$ equipes passarão a receber $\mathrm{V}$ por cada equipe por ano", a regra passaria a ser formulada de outro modo, a saber, "os municípios que chegarem a ter $Y$ pessoas cadastradas no PSF passarão a receber $\mathrm{V}$ por cada equipe por ano", onde

$$
\mathrm{Y}=\mathrm{X} \times 3.450 \text {. }
$$

Nesse caso, as grandes cidades que utilizassem um parâmetro menor que 3.450 pessoas por equipe e alcançassem o patamạr do número de pessoas cobertas só atingiriam o patamar $(\mathrm{Y})$ com um pouco mais de $(\mathrm{X})$ equipes. Estariam assim em situação idêntica àquela em que se encontram hoje os municípios rurais que adotam aqueles parâmetros mínimos.

Outra alternativa seria explicitar que os municípios só farão jus a tal incentivo por número de equipes acima de um patamar, ou número absoluto de habitantes cobertos pelo PSF, no caso de adotarem um parâmetro de, digamos, 3.000 pessoas para cada equipe de saúde da família. Isso significa estabelecer uma norma específica para o número de pessoas acompanhadas por cada equipe.

Algumas objeções poderiam ser feitas a esse tipo de incentivo dirigido às grandes cidades. Poder-se-ia objetar afirmando, por exemplo, que, se tais critérios poderiam incentivar um início mais expressivo do PSF nas grandes cidades, eles não ofereceriam atrativos adicionais para a contínua elevação da cobertura do PSF nas cidades muito populosas. O argumento é falacioso, pois só leva em consideração uma das dimensões do incentivo, esquecendo que o valor per capita do incentivo seguirá elevando-se com aumentos de cobertura adicionais (sem falar na maior proporção do $\mathrm{PAB}$ fixo que se volta para o PSF, na medida em que o caráter substitutivo do PSF se torna mais real). É claro que tal incentivo permite um ritmo mais gradual de crescimento adicional. Essa graduação, a partir de um patamar de centenas de milhares de pessoas cobertas, não é de todo indesejável. Há efeitos ainda não explorados de uma rápida elevação do número de equipes nas grandes cidades, que recomendam cautela no ritmo de crescimento do PSF, sobretudo nas cidades mais populosas (um processo seletivo para constituir 500 
equipes numa grande cidade talvez provocasse um esvaziamento de equipes do PSF de cidades menores, por exemplo).

E outra possível objeção seria em relação ao aumento do volume de recursos federais destinados ao PSF, no caso de tal critério ser criado. Aqui o argumento também é falacioso. É claro que o volume de recursos do Governo federal define a escolha de um patamar do número de equipes e de um valor para o pagamento por equipe. Conforme essas definições, há um aumento das despesas com a nova forma de cálculo para os municípios que hoje já têm o número de equipes acima do(s) patamar(es) estabelecido(s). Trata-se de um tipo de ajuste inicial, um tipo de custo de implantação do novo critério, que pode ser medido com certa precisão, desde que definidos os critérios operacionais. Mas o efeito do incentivo se fará sentir se o gasto for maior que o incentivo inicial. Não se promoverá o PSF sem ampliar o volume de recursos gastos com o PSF. Se a cobertura de $100 \%$ é desejável e as regras do incentivo são sustentáveis, o Governo federal deve ter em vista que, para tal, deverão estar implantadas cerca de 50 mil equipes de saúde da família no Brasil, o que envolverá, pelos critérios atuais, cerca de $\mathrm{R} \$ 2.700 .000 .000,00$ no incentivo do PSF.

O Governo federal tem dado mostras de que caminha nessa direção, não hesitando em aportar mais recursos para o incentivo do PSF. Qualquer hesitação do governo, contudo, pode corroer o potencial indutor do incentivo, pois poderia ser lido como uma forma de desencadear experiências de PSF, para depois reduzir a contribuição do Governo federal no custeio dos programas já implantados.

Dado o patamar atual de recursos e na hipótese da real importância do PSF para o Governo federal, não há, entretanto, razões para julgar que a falta de receita constitua fator impeditivo à construção de tal tipo de incentivo, caso haja vontade política de atacar o âmago da questão do acesso da população das grandes cidades a uma atenção integral à saúde de qualidade.

Se a argumentação deste trabalho for bem compreendida, não há como evocar a restrição financeira ou a incapacidade de formulação de alternativas adequadas de financiamento, em defesa do status quo. Muitos são os obstáculos no caminho das mudanças que se fazem necessárias. Mas o roteiro da transformação já é conhecido. 


\section{Referências Bibliográficas}

BANCO MUNDIAL. Relatório sobre o Desenvolvimento Mundial 1993: Investindo em Saúde. Rio de Janeiro: Fundação Getúlio Vargas, 1993. BRASIL. Ministério da Saúde. Programa de Saúde da Família: saúde dentro de casa. Brasília: Ministério da Saúde, 1994.

- Portaria 2203, de 5 de novembro de 1996. Diário Oficial, de 6 de novembro de 1996, p. 22932-22940. Apresenta como anexo a Norma Operacional Básica do Sistema Único de Saúde - NOB-SUS 01/96.

Portaria 1886, de 18 de dezembro de 1997. Diário Oficial, de 22 de dezembro de 1997, p. 11-13).

. Portaria 157, de 19 de fevereiro de 1998. Diário Oficial, de 26 de março de 1998, p. 104.

. Portaria 1329, de 12 de novembro de 1999. Disponível em: <www.saude.gov.br/portarias/1999.htm>. Acesso em: 11 nov. 2001.

. Portaria 1013, de 8 de setembro de 2000. Disponível em: $<$ www.saude.gov.br/portarias/2000.htm>. Acesso em: 11 nov. 2.001.

LEVCOVITZ, E.; GARRIDO, N.G. Saúde da Família: a procura de um modelo anunciado. Cadernos de Saúde da Família, ano I, n ${ }^{\circ} 1$, p. 3-9, jan/ jun. 1996.

LEVCOVITZ, E.; LIMA, L.D.; MACHADO, C.V. Política de saúde nos anos 90: relações intergovernamentais e o papel das Normas Operacionais Básicas. Ciência \& Saúde Coletiva, v. 6, n. 2, p.269-291, 2001.

PINHEIRO, R.; MATTOS, R. A . Os sentidos da integralidade na atenção e no cuidado à saúde. Rio de Janeiro: ABRASCO, 2001.

MATTOS, R. A. Desenvolvendo e Ofertando Idéias: um estudo sobre a elaboração de propostas de política de saúde no âmbito do Banco Mundial. 2000. Tese (Doutorado em Saúde Coletiva) - Instituto de Medicina Social, Universidade do Estado do Rio de Janeiro. 


\section{NOTAS}

1 Professor adjunto do Instituto de Medicina Social da UERJ, Doutor em Saúde Coletiva.

2 Chamamos aqui de grandes cidades aquelas com mais de 100 mil habitantes. No Brasil, segundo dados do Censo 2000, existem 224 grandes cidades, que em conjunto concentram mais da metade da população brasileira.

3 Privilegiamos, neste trabalho, o incentivo do PSF \& não o do PACS. Julgamos útil distinguir - PACS que se expande para além do PSF, do PACS cuja abrangência se superpõe ao PSF. Acolhemos a idéia de que a última situação é desejável.

4 A expressão "eficazes em termo de custo" difundiu-se enormemente com o relatório Investindo en Saúde (Banco Mundial, 1993) e tem sido utilizada para indicar um critério que pode ser útil para elaborar pacotes seletivos de intervençōes de saúde. Em outro trabalho (Mattos, 2000), no qual examinamos detalhadamente a construção das propostas de política de saúde no âmbito do Banco Mundial, mostramos que o termo poderia ser adequadamente utilizado para adjetivar as intervenções apoiadas pelo Unicef na década de oitenta.

5 Logo se vê que a noção de agente comunitário foi desenvolvida tendo em vista o acesso a comunidades com precárias condições de vida. A adequação da proposta de agentes comunitários de saúde em comunidades que não apresentam condições precárias de vida em um país marcado pela desigualdade pode ser posta em xeque. Com efeito, se o agente comunitário é recrutado entre as camadas menos privilegiadas da população, seu trabalho junto a pessoas de outros grupos sociais mais favorecidos recoloca a distância cullural e social que a invenção do agente comunitário pretendia remover.

6 Para uma discussão mais detalhada das várias acepções da integralidade, ver Pinheiro e Mattos (2001).

7 Se o PACS sem PSF é uma estratégia provisória de expansão do acesso ao sistema, a expansão do PSF não exige a existência prévia de agentes comunitúrios. Por sua vez, onde existe o PSF, os agentes comunitários se vinculam à equipe de saúde da família.

8 Assim o então Ministro da Saúde, Henrique Santillo, dizia, na apresentação do primeiro documento publicado sobre o novo programa, que o mesmo atenderia "principalmente aos 32 milhöes de brasileiros incluidos no Mapa da Fome do IPEA, expostos a maior risco de adoecer e morrer e na sua maioria sem acesso permanente aos serviços de saúde" (Brasil, 1994, p. 5).

9 Uma forma embrionária de incentivo ao PSF, através do pagamento diferenciado da produção das equipes, foi de fato implantada provisoriamente, enquanto a discussão sobre a NOB 96 avançava. A idéia, entretanto, era incentivar o programa como um todo, c não a produçāo, inserindo tal incentivo no contexto das novas propostas de piso para atenção básica.

10 O Governo federal optou por separar os incentivos do PSF e do PACS. O primeiro é voltado para o custeio dos demais elementos da equipe de saúde da família que não os agentes comunitários, e o segundo, voltado para a contribuição no custeio dos agentes comunitários, quer eles sejam ou não vinculados ao PSF. Deste modo, enquanto o incentivo específico do PSF guarda uma relação direta com os propósitos de reorganização da atenção básica e de universalização do PSF, o incentivo do PACS se aplica indistintamente tanto nas situações nas quais o PACS sem PSF é uma estratégia que se quer provisória de extensāo da cobertura do sistema de saúde, no velho espírito dos cuidados primários de saúde, quanto nas situações em que os agentes comunitários integran a equipe de saúde da família. É exatamente por isso 
que, neste trabalho, enfatizamos o incentivo específico do PSF. A isso se acrescenta que a expansāo da cobertura do PACS não parece ser tão complexa quanto a do PSF, pelo menos a julgar pelas diferentes coberturas dos dois programas.

11 Trabalhamos com o valor das transferências por habitante por ano, o que nos permite comparar os valores do incentivo per capita com os do PAB fixo.

12 Esse valor corresponderia a um município que mantivesse a cobertura de cinquienta por cento ao longo do ano.

13 É claro que os raciocínios que desenvolveremos adiante podem ser refeitos de modo análogo para qualquer outro parâmetro de cobertura de uma equipe de saúde da família, o que, mesmo mudando os valores do incentivo per capita, nāo modificará os formatos da curva nem as conclusões desta análise.

14 Supondo um salário de um médico de cerca de três mil reais, do enfermeiro de cerca de dois mil reais e do auxiliar de enfermagem de cerca de quinhentos reais, sem considerar a remuneração dos agentes comunitários, sem quaisquer encargos, e considerando que uma equipe atende a 3.450 pessoas, chegaríanos a um patamar de cerca de vinte reais por pessoa coberta por ano.

15 Esse é o diferencial das duas primeiras faixas da Portaria n. 1.329, expresso em valor por habitante coberto para um parâmetro de 3.450 pessoas acompanhadas por uma equipe.

16 O cálculo desses valores é bastante simples. Parte-se de um parâmetro de cobertura de uma equipe de saúde da família (aqui utilizamos o tradicional 3.450 pessoas por equipe) e multiplica-se pelo patamar proposto de número de equipes $X$ (nos exemplos, 100,50 e 20 , respectivamente) para calcular o número de pessoas que seriam cobertas por essas $\mathrm{X}$ equipes. Ora, serão beneficiados pelo critério proposto os municípios para os quais o total de pessoas cobertas pelas $X$ equipes corresponder a menos do que $70 \%$ da população. Dividindo-se o número de pessoas cobertas pelas $X$ equipes por 0,7 , teremos o número de habitantes a partir do qual um município passaria a se beneficiar do critério. 


\section{ABSTRACT}

Incentives for the Family Health Program and the impact on large cities

This study discusses the issue of financial incentives for the Family Health Program (PSF) in Brazil, from the perspective of adapting the incentives to the need for expanding the PSF in large cities. We begin by analyzing the context in which the proposal for incentives was formulated and the reasons for emphasizing coverage of the PSF, and proceed to discuss the criterion for calculating the prevailing financial incentive, analyzing the extent to which it contemplates the needs of administrators in large cities. Finally, we indicate a range of possibilities for introducing new rules that raise the level of payment by the Federal government per PSF team based either on a given number of teams implemented or an absolute number of individuals covered by the Program, while maintaining the current criteria for all the municipalities that have still not reached this threshold.

Keywords: Family Health Program; Financing Public Policies; Health in Large Cities

Recebido em: 26/05/02

Aprovado em: 10/06/02 
Gúfico 1. Valores do incentivo do PSF em reais por habitante por ano, em fungão da octertura, segundo critérios da portaria 1329.

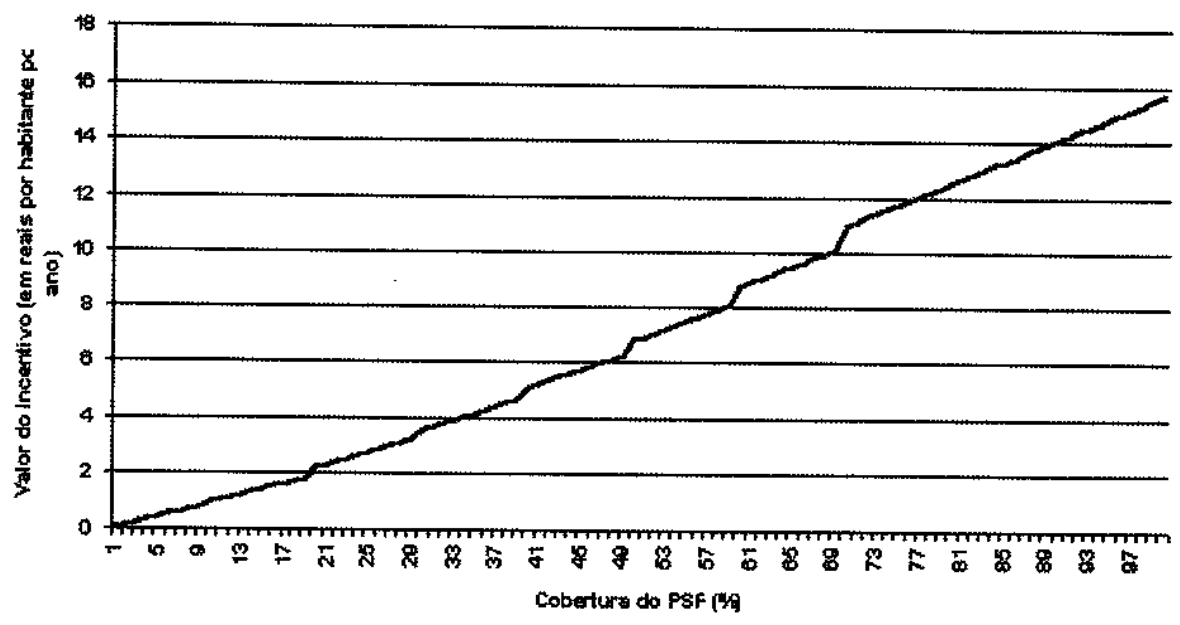

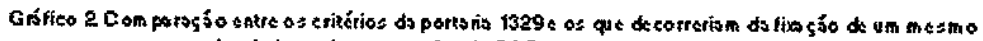
yator de incentivo por equje do PSF (V)pors qustajer coberuro

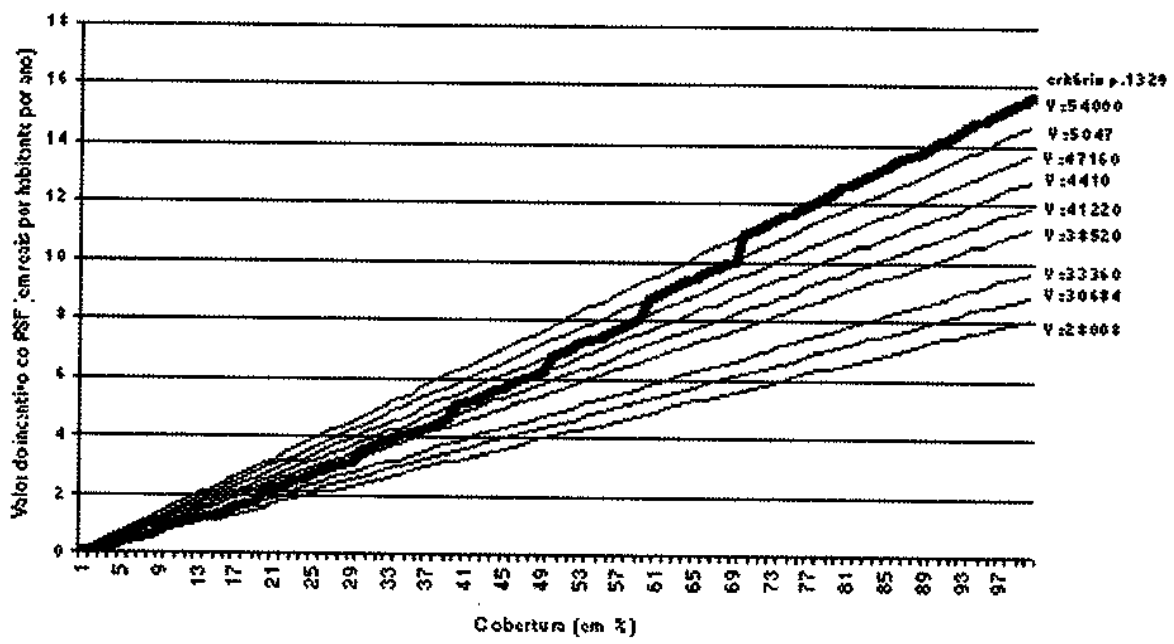


Quadro 1: Faixas de remuneração por equipe por ano, segundo a Portaria n. 1.329.

\begin{tabular}{|c|c|}
\hline $\begin{array}{c}\text { Faixas de cobertura (C) } \\
\text { (em decimais) }\end{array}$ & $\begin{array}{c}\text { Valor do incentivo por } \\
\text { equipe por ano (V) }\end{array}$ \\
\hline 0,00 e 0,049 & $\mathrm{R} \$ 28.008,00$ \\
0,05 e 0,099 & $\mathrm{R} \$ 30.684,00$ \\
0,1 e 0,199 & $\mathrm{R} \$ 33.360,00$ \\
0,2 e 0,299 & $\mathrm{R} \$ 38.520,00$ \\
0,3 e 0,399 & $\mathrm{R} \$ 41.220,00$ \\
0,4 e 0,499 & $\mathrm{R} \$ 44.100,00$ \\
0,5 e 0,599 & $\mathrm{R} \$ 47.160,00$ \\
0,6 e 0,699 & $\mathrm{R} \$ 50.472,00$ \\
0,7 ou mais & $\mathrm{R} \$ 54.000,00$ \\
\hline
\end{tabular}




\begin{tabular}{|l|c|c|c|}
\hline \multicolumn{4}{|c|}{$\begin{array}{c}\text { Quadro 2: Valores de incentivo por habitante coberto para } \\
\text { cada uma das faixas de cobertura definidas } \\
\text { na Portaria n. 1.329 }\end{array}$} \\
\hline $\begin{array}{l}\text { Faixas de } \\
\text { cobertura } \\
\text { (em \%) }\end{array}$ & $\begin{array}{l}\text { Valor do incentivo } \\
\text { em reais por } \\
\text { habitante coberto } \\
\text { por ano (se cada } \\
\text { equipe acompanha } \\
\text { 3.450 pessoas) }\end{array}$ & $\begin{array}{l}\text { Valor do incenti- } \\
\text { vo em reais por } \\
\text { habitante coberto } \\
\text { por ano (se cada } \\
\text { equipe acompa- } \\
\text { nha } 4.500\end{array}$ & $\begin{array}{l}\text { Valor do incenti- } \\
\text { vo em reais por } \\
\text { habitante coberto } \\
\text { por ano (se cada } \\
\text { equipe acompa- } \\
\text { nha 2.400 } \\
\text { pessoas) }\end{array}$ \\
\hline 0 a 4,9 & 8,12 & 6,22 & 11,67 \\
\hline 5,0 a 9,9 & 8,89 & 6,82 & 12,79 \\
\hline 10 a 19,9 & 9,67 & 7,41 & 13,90 \\
\hline 20 a 29,9 & 11,17 & 8,56 & 16,05 \\
\hline 30 a 39,9 & 11,95 & 9,16 & 17,18 \\
\hline 40 a 49,9 & 12,78 & 9,80 & 18,38 \\
\hline 50 a 59,9 & 13,67 & 10,48 & 19,65 \\
\hline 60 a 69,9 & 14,63 & 11,22 & 21,03 \\
\hline 70 ou mais & 15,65 & 12,00 & 22,50 \\
\hline
\end{tabular}


Quadro 3: Número de equipes de saúde da família necessário para que municípios com certas populações mudem de faixa de remuneração das equipes do PSF

\begin{tabular}{|l|l|l|l|l|l|l|l|}
\hline $\begin{array}{l}\text { Municí- } \\
\text { pio com } \\
100.000\end{array}$ & $\begin{array}{l}\text { Valores do } \\
\text { incentivo } \\
\text { por equipe }\end{array}$ & $\begin{array}{l}\text { Municí- } \\
\text { pio com } \\
250.000\end{array}$ & $\begin{array}{l}\text { Municí- } \\
\text { pio om } \\
500.000\end{array}$ & $\begin{array}{l}\text { Municí- } \\
\text { pio com } \\
750.000\end{array}$ & $\begin{array}{l}\text { Município } \\
\text { com } \\
1.000 .000\end{array}$ & $\begin{array}{l}\text { Município } \\
\text { com } \\
5.000 .000\end{array}$ & $\begin{array}{l}\text { Município } \\
\text { com } \\
10.000 .000\end{array}$ \\
\hline 2 & 30.684 & 4 & 8 & 11 & 15 & 73 & 145 \\
3 & 33.360 & 8 & 15 & 22 & 29 & 145 & 290 \\
6 & 38.520 & 15 & 29 & 44 & 58 & 290 & 580 \\
9 & 41.220 & 22 & 44 & 66 & 87 & 435 & 870 \\
12 & 44.100 & 29 & 58 & 87 & 116 & 580 & 1160 \\
15 & 47.160 & 37 & 73 & 109 & 145 & 725 & 1450 \\
18 & 50.472 & 44 & 87 & 131 & 174 & 870 & 1740 \\
21 & 54.000 & 51 & 102 & 153 & 203 & 1015 & 2029 \\
\hline
\end{tabular}

